\title{
The meaning of sexuality for the spouse caregiver of the elderly person with Alzheimer's disease
}

\author{
Significado da sexualidade para o cônjuge cuidador de pessoa idosa com doença de \\ Alzheimer
}

Marta Gabriele Santos Sales ${ }^{1}$, Tânia Maria de Oliva Menezes²

\begin{abstract}
Objective: to understand the meaning of sexuality for the spouse caregiver of the elderly person with Alzheimer's disease. Methods: qualitative study with eight spouses of elderly Alzheimer's patients by means of semi-structured interviews in households. The content analysis technique was used for systematic analysis of interviews and categorization of statements. Results: two categories were seized: 1 . Understanding of sexuality; 2. Meaning of sexuality after the Alzheimer's disease of the spouse. The testimonials revealed a lack of knowledge about the term "sexuality", as well as the shame of talking about the subject. Sexuality was present in the lives of some and abolished in the lives of others. Conclusion: there are positive and negative aspects of the impact of the disease on sexuality. They make this population vulnerable to various conflicting situations with the self and with the marital relationship.
\end{abstract}

Descriptors: Nursing; Sexuality; Alzheimer Disease.

Objetivo: compreender o significado da sexualidade para o cônjuge cuidador de pessoa idosa com doença de Alzheimer. Métodos: estudo qualitativo, com oito cônjuges de idosos com doença de Alzheimer, por meio de entrevista semiestruturada nos domicílios. Utilizou-se a análise de conteúdo como técnica de análise sistemática das entrevistas para categorização dos depoimentos. Resultados: apreendidas duas categorias: 1. Entendimento sobre sexualidade; 2. Significado da sexualidade após a doença de Alzheimer do cônjuge. Os depoimentos obtidos revelaram falta de conhecimento acerca do termo "sexualidade", bem como a vergonha de falar sobre o tema. A sexualidade esteve presente na vida de alguns e foi abolida da vida de outros. Conclusão: há aspectos positivos e negativos da doença que repercutem na sexualidade do casal, o que torna essa população vulnerável as diversas situações de conflito consigo mesmo e em sua relação conjugal.

Descritores: Enfermagem; Sexualidade; Doença de Alzheimer.

\footnotetext{
${ }^{1}$ Obras Sociais Irmã Dulce. Salvador, BA, Brazil.

${ }^{2}$ Universidade Federal da Bahia. Salvador, BA, Brazil.

Corresponding author: Tânia Maria de Oliva Menezes

Rua Basílio da Gama S/N - Campus Universitário - Canela. CEP. 40110907. Salvador, BA, Brazil. E-mail: tomenezes50@gmail.com
} 


\section{Introduction}

Although the mechanisms underlying the aging process are not yet fully understood, this is considered an important risk factor for Alzheimer's disease, affecting about 5,400,000 US citizens ${ }^{(1)}$. Given this scenario, we can say that Alzheimer's disease is the most common neurodegenerative disease. As a matter of fact, this disease generates a cost of 385 million US dollars per year. It is estimated that one in eight people older than 65 years can develop the disease, as well as 40 to $50.0 \%$ of the people older than 85 years, and more than $50.0 \%$ of the long-lived subgroup ${ }^{(2)}$.

Approximately 50 to $80.0 \%$ of people over the age of 60 years are sexually active, and normal sexual activity continues until the eight decade of life $^{(3)}$. Despite the sexuality of the elderly person still is a taboo for society and even for the elderly themselves, sexual desire doesn't change with age, and the elderly can continuously enjoy sex life as long as the desire doesn't change ${ }^{(4)}$.

Sexuality is thereby a part of the human nature throughout the life cycle. The impact of dementia on the sexuality and intimacy of the couple can cause tension and insecurity for both ${ }^{(3)}$.

So, understanding that the main caregivers of seniors with Alzheimer's disease are the spouses, it is necessary to understand the effects of dementia on the couple's sexuality. Alzheimer's disease creates many difficulties for spouses who care for their partners. The problems include the deterioration of the quality and satisfaction with the relationship, and of the emotional and physical intimacy of the couple ${ }^{(5)}$.

Thus, considering the growth of Alzheimer's disease in elderly people worldwide and in Brazil, the better understanding of the marital relationship requires a reflection on the marital state, the significance of sexuality and, in addition, the presence of a chronic-degenerative disease in their lives. In this context, the objective of this study was to understand the meaning of sexuality for the spouse caregiver of elderly Alzheimer patients.

\section{Methods}

Qualitative study that sought to explore the universe of meanings and allowed to learn the reality experienced by the spouse caregivers of elderly Alzheimer patients. The purpose was to obtain answers on the objective proposed, as well as establish familiarity between the researcher and the researched theme, which is still little known and explored.

The survey started in the 13th Regional Health Board, through the Drugs of Exceptional Dispensation Program, responsible for the supply of high-cost medicinal products for patients with diseases such as Alzheimer's. A survey of people enrolled in this program was made, and the potential participants of the research were selected. Finally, after a telephone contact and upon receiving permission of a responsible person, the house of the elderly was visited and this represented the last research scenario, where the actual contact with the collaborators took place, for collection of statements.

The survey of people registered by the Drugs of Exceptional Dispensation Program identified 86 people with Alzheimer's disease exclusively in the city of Jequié, in the state of Bahia, in northeastern Brazil. A telephone contact was made with all these persons. Finally, among the 86 individuals, there were 19 elderly people with Alzheimer's disease whose spouses had died, three people who are separated, one person with other diagnosis than Alzheimer's disease, two people who had no telephone contact on the registration files, one case in which the elderly person with Alzheimer's disease had died, two collaborators were ill, five had addresses in the city of Jequié but lived in neighboring districts actually, and 15 people with the errors in the telephone contact. Data collection took place between July and August 2014.

Among the 38 patients who made part of the sample, only eight met the inclusion criteria to participate in the study: spouse of a Alzheimer patient with confirmed diagnosis, regardless the etiology and the stage; preserved cognitive capacity to respond to the 
interview. The exclusion criterion consisted in the lack of success in locating the spouse at home after three telephone call attempts.

Participants were approached by telephone call, by means of which was given the explanation on how the contact was obtained and what were the objectives of the research. After these explanations, the invitation to participate was made. Then, a home visit for collection of testimonials was scheduled in day and time chosen by the participant. Interviews were conducted preferably by the researcher and directly with the elderly person, except in one interview where that the elderly person requested the presence of a family member.

Testimonials were collected through semi-structured interviews with aid of a previously prepared script and with an audio recorder. The main issues were: (1) How do you see your spouse today? (2) What do you understand by sexuality? (3) Talk about your sexuality; and (4) What is the meaning of sexuality for you after the Alzheimer's disease of your spouse?

Thematic content analysis was used for analysis of statements. The different stages of this analysis followed the three poles of organization. After transcribing the interviews, these were read in two different moments to better understand the reports.

Later, a third reading was carried out for identifying the key points of the reports, which responded to the objective proposed in the study, according to the foreknowledge of the researcher. Despite finding these points in all the interviews, some important aspects to contemplate the objective were identified only in some reports, but they were still considered. Finally, the lines were grouped according to similarity of content and organized into categories, which would be discussed along with literature on the subject in question, for better theoretical basis. In order to preserve the anonymity of participants, fictional names of stars were assigned to them.

The study complied with the formal requirements contained in the national and international regulatory standards for research involving human beings.

\section{Results}

Among the eight seniors who composed the sample, females predominated, with five participants. Ages ranged between 60 and 95 years; two had no schooling and six had between one and nine years of study. As for religion, three were five Catholics and five Evangelicals. As for being a caregiver, five were the primary caregivers to their spouses and the time of diagnosis of Alzheimer's disease varied from two to 10 years.

The speeches led to the creation of two categories: Understanding of sexuality and Meaning of sexuality after the Alzheimer's disease of the spouse.

\section{Category 1 - Understanding of sexuality}

The question on what participants understand by sexuality resulted in a variety of definitions. Among them, the lack of knowledge about the term was evident, as the following lines demonstrate: Yes. What is it sexuality, precisely? (Hassaleh). My daughter, Oh, I don't even know how to answer you (Acrux).

The lack of knowledge can be a result of stereotypes about sexuality in old age imposed by society, in which there is the myth of asexual old age.

One participant felt embarrassed to report the definition of sexuality and requested the presence of her niece in the collection. The niece said that aunt was embarrassed to answer. As the line below shows, she initially refused to answer, claiming that she did not know, but after all, she eventually gave a definition: It's something that I don't know. I won't know how to answer that. It's love (Alya).

Myths about asexual old age also associate the expressions of sexuality to feelings of shame, fear and decency, as expressed by Alya. People, in general, avoid talking about their sexual experiences and deve- 
lop a reserved attitude towards this subject.

Another indispensable factor for the understanding of this unexplored universe of sexuality of old couples is the repression of sexuality, as a result of the partner: That's it for me, I'm saying, I don't know how to tell you, because he is the sort of person that, he was all the time like this, without love (Polaris).

This omission leads the person to avoid the confrontation between the impulses and the refusal of the spouse who never expressed feelings of love throughout the life, in this case, regardless of the disease. For Polaris, love is the base of sexuality, whereas this is totally meaningless, because of the deprivation from love from the spouse.

However, other participants reported various definitions of sexuality: Love, the relationship, you know. Sometimes, that wish you have to make things you know? (Marfik). It's an expression of affection, right? It's sex. A love (Nashira). Ah, sexuality is pleasure of life. It's sex. For the person who doesn't have fun, how will this person live? (Antares).

Each elderly person understands sexuality according to her or his experience, as evident in the diversity of definitions expressed in the survey. Some respondents did not know the meaning of the word. For others, sexuality was just sex. Some included love, desire, care, pleasure, fun or necessity of life.

As this is a subjective topic, each person characterized sexuality according to his/her experiences. However, it is noticed that sex and sexuality are regarded as synonymous. Although sexuality is referred as an expression of affection, love and fun, the elderly put sexuality and sexual intercourse in the same definition.

However, it is in old age that sexuality is experienced in the most different forms. That can happen in the relations of friendship, complicity and intimacy. Understanding the universe of sexuality in old age and based on interviews conducted in the present study, expressions of sexuality in the everyday life are evidently experienced with the spouse who is affected by Alzheimer's disease. Positive and negative aspects were identified in the impact of the disease on the se- xuality of the couple: I like to get ready, pretty, even today. I like to buy my beautiful necklaces, earrings, matching them, my shoes. I like to put my things all looking well together in me. I always liked to do that (Alya).

Even before the spouse be affected by Alzheimer's disease, Alya had the custom of dressing up well and that hasn't changed after the diagnosis of her spouse. The fact that she likes dressing up, buying earrings and matching shoes is closely related to her sexuality. Vanity is part of this universe, positively interfering in the well-being, as well as influencing the marital relationship. Thus, vanity, an expression of sexuality of Alya is one of the positive impacts identified in the research.

\section{Category 2 - Meaning of sexuality after the Alzheimer's disease of the spouse}

The testimonials revealed that the practice of sexuality was not discontinued despite the presence of the disease, as explained below: Just the bath, she doesn't bathe alone, no, she bathes with me, but it has to be this way. Is it not two of us? He passes the soap in me, and I do it in him. We take shower together, so we go on the life (Hassaleh).

These speeches disclose that there is a change in the ability to perform activities of daily living, such as bathing, as a result of Alzheimer's disease in the case of Hassaleh's wife. This change led him, as spouse, to find an alternative to resolve the problem in the best possible way that was taking the shower with her. In the interview, he mentioned that his wife agreed to the alternative used. "Taking shower together" leads us understand also that despite modifications in the body, with physical limitations and aesthetic changes, typical of aging, there still exists the expression of sexuality.

However, beyond this expression of sexuality and of the positive aspects that we have seen so far, there is the opposite side of this experience: Sex life is very difficult with her today, in sexualty, she has stopped. She stopped. Stopped (Marfik). I no longer feel these needs. This was because I asked God very much, for Him to take it over, so that I don't feel it 
anymore. A long time ago (Polaris). He does not seek me for nothing at all. Not now, about three years back, he wasn't seeking for anything else, no. It's like that started fading, isn't it? Because there's no disease to stop it, no, he gets very shameless when he wants it. He is now 83, 84 years, so, but, he has not yet out of the game, no (Antares). After Alzheimer's disease, you don't feel anything, no. Nothing. That's it. Over. Before the disease, it was all about it, right? You have more love, more tenderness for the person, but then no, no longer has that warmth, that kiss, that hug. It's colder, it's cold. Everything changes, too much. Oh, my (sexuality) I forgot, I put it in a very deep hole and buried it. You forget that (Nashira).

The lines show the negative aspects of Alzheimer's disease on the sexuality of the couple. Marfik expressed difficulty in maintaining sex life with his wife after Alzheimer's. He said specifically that sex no longer exists as a result of the disease. In turn, for Polaris, it is obvious that his wife no longer have sexual desires for the husband. His alternative in the face of so much suffering was to constrain his desires, so he would not suffer any longer. Like most participants, Antares is no different. She brought up the lack of sexual activity as the main negative factor that the disease caused in the expression of sexuality with her husband.

Nashira raises other issues of sexuality. She says that, after her spouse was diagnosed with Alzheimer's, many things have changed. The feelings and actions, like love and a kiss, are no longer the same, and that those things meant everything to her, bringing satisfaction with her sexuality before the illness of the spouse. However, before this change, her reaction was to abandon and completely forget her sexuality, i.e. she buried her love, the coziness, the kiss and the hug, remaining only the affection from a long life lived together and, who knows, of the moral duty of having to take care of the husband, as vowed at the altar on their wedding day.

However, it notable that even unaware of their actions, the elderly person with Alzheimer's disease does not lose completely sexuality or sexual desires: The thing is, I won't deny it, she is very loving. Very loving really. Inside, all the time is kissing me, taking me around, is looking for a little chat, a game, something (Hassaleh). Sporadically, at one time or another, she feels the need (sex). We start working on it. But, the day to day is very difficult (Marfik).

\section{Discussion}

The study presented some limitations with regard to the reality of a city in the countryside of Bahia, making it difficult to generalize the findings to other social contexts. Another limitation refers to the qualitative method adopted, which allows the in-depth analyses, but with a limited number of participants. Thus, it is necessary to carry out further research on the theme in order to contemplate aspects that were not addressed by the present study.

Questions about intimacy and sexuality, particularly experienced by older people with cognitive impairment, need to be further explored by researchers of the health area ${ }^{(6)}$. Aging is inherent in the human being and sexuality issues need to be discussed in the course of all life stages ${ }^{(7)}$. The way individuals with chronic illness experience their own sexuality and the consequences for the sexuality of their partner should be better understood, knowing that such circumstance does not diminish their needs neither their desires for sexual gratification and human partnership ${ }^{(6)}$. The investigation of this theme showed that research studies on sexuality among elderly couples in which one partner has Alzheimer's disease are still rare in Brazil.

Sexuality is hard to conceptualize, because it is an issue linked to very personal experiences. The presence of chronic diseases such as Alzheimer's can deprive the elderly from important aspects such as sexuality, becoming a theme not only little discussed, but also short lived.

As for the expressions of sexuality, a high level of intimacy of the couple before diagnosis is a key factor for mitigating the negative effects on the provision of care. An opposite situation was found in a survey where the spouse caregiver internalized his/her manifestations of sexuality, before the possibility that these would slip into disappointment and frustration. 
Thus, what can be observed is that the way the marital relationship is lived before diagnosis directly influences the way the spouse takes care of his/her partner with Alzheimer's. The understanding of the role of intimacy between couples affected by diseases such as Alzheimer's can contribute to help them reduce the effects of this care ${ }^{(8)}$.

Another study emphasizes the idea that the poor quality of the relationship previous to the disease is associated with depression, poor quality of life and less satisfaction in providing care, while caregivers who had highly intimate relationships were less likely to criticize the process of $\operatorname{care}^{(3)}$.

The concept of sexuality as simply sex, found in the research, can be the result of the education that the elderly have received in the past, or of the influence of society itself. Society imposes the burden of asexuality on the old age, causing regresses in the way of acting and expressing themselves when it comes to sex $^{(9)}$. Sex and sexuality are presented as synonyms, perhaps by the prejudices experienced during youth. Despite this, the research evidenced sexuality as something beyond sexual intercourse.

Study points that the expression of sexuality consists in something wider, a dimension inherent in the person, present in every act of life and the personal mode of each person of being and acting. However, it is stated that this broader view of sexuality would fit best the experiences of older people, but there is currently no consensus on it ${ }^{(3)}$.

As for the positive aspects found, such as the maintenance of some customs, the abovementioned study says that in cases of dementia, the intimacy can compensate functional and cognitive losses, which reduce the esteem of the individual ${ }^{(3)}$. Furthermore, the fact that participants give importance to their body contradicts what society values, showing that sexuality is expressed beyond the sexual act and does not prioritize the stereotype of body care imposed by society.

The elderly person, regardless of being sexually active or not, has a sexuality seized, which can be ex- pressed in other ways, not only in the sexual act. The fact that society ignores this theme turns out to instill biased ideas ${ }^{(9)}$. Therefore, a better acceptance of sexuality in old age is expected, especially with more naturalness, since this is part of the health and well-being of the elderly ${ }^{(10)}$.

In the American society, the sexually desirable woman is young and slim, in contrast with the old woman, who has her physical appearance transformed by wrinkled skin and weight gain ${ }^{(11)}$.

On the other hand, the downside of that experience appeared in the study when participants said that there is a drop in the aspects related to sexuality, primarily by the lack of interest of the partner who has dementia. In these cases, care is unsatisfactory and there are great chances that the spouse develop health problems After all, they are reluctant to express their sexual difficulties and seek help ${ }^{(11)}$. The daily life of providing care brings repercussions in the caregiver's health conditions. These include hypertension, changes such as headache and lumbar pain and demonstrations that indicated the presence of depression ${ }^{(12)}$. These modifications could compromise the expression of sexuality of the caregiver, a problem that increases over time.

Behavioral problems, including inappropriate sexual behavior are distressing for patients and their caregivers, and may reflect the predominant behavior accompanying dementia: disinhibition, or apathy associated to hipossexuality ${ }^{(13)}$. On the other hand, we need to consider that increased cognitive, environmental and physical deficiencies can prevent the ability to express and experience intimacy and sexuality of people with dementia ${ }^{(14)}$.

Before the conflict of expressing the sexual difficulties with their partners to the health professional, this must investigate the sexual history of the couple, as well as assess the current state of the physical and emotional relationship of these elderly. After all, this information is of great relevance to the comfortable and unbiased dialogue between professionals and participants, which could limit the ways of 
solving these problems ${ }^{(8)}$. Nursing professionals have to be present in the continuous sexual assistance to the elderly, as a way of health and psychosocial well-being ${ }^{(10)}$, depending on the gender of the caregiver, the satisfaction with the intimacy and the cognitive level of the Alzheimer patient, which significantly contribute to the well-being of the caregiver ${ }^{(15)}$.

The sensitivity to care is extended in the sense that care is not necessarily the practice of procedures, but also feeling that care can be accomplished with attitudes of subjectivity and, by understanding that care is not linear, but can adapt to the different situations faced in daily life $\mathrm{e}^{(16)}$.

However, it is obvious that the spouse feels embarrassed at times and finds difficulties in dealing with certain situations, when the partner with Alzheimer's disease manifest sexual desires. In general, a person with this disease has no conscience of his/her attitude. Thus, to deal with such a situation, the spouse has to come to an agreement with the own feelings and try to solve the various sexual changes that Alzheimer's disease may cause to the partner.

In this context, it is necessary that the nurse widen the assistance to the spouse caregiver because sometimes this person doesn't have visibility to the health system, discussing and advising on issues involving sexuality.

\section{Conclusion}

The study highlighted various meanings of sexuality for the spouse caregiver of elderly Alzheimer patients. These make this population vulnerable to the more diverse and conflicting situations with the self and with the marital relationship, requiring multidisciplinary support in primary care, hospital or home.

\section{Acknowledgements}

To the Coordenação de Aperfeiçoamento de Pessoal de Nivel Superior by granting the master's scholarship.

\section{Collaborations}

Sales MGS participated in the design of the project, collection, analysis and interpretation of data, writing of the article and approval of the final version to be published. Menezes TMO contributed to the analysis and interpretation of data, writing of the article and approval of the final version to be published.

\section{References}

1. Mao P, Reddy PH. Aging and amyloid beta-induced oxidative DNA damage and mitochondrial dysfunction in Alzheimer's disease: Implications for early intervention and therapeutics. Biochim Biophys Acta. 2011; 1812(11):1359-70.

2. Swerdlow RH. Brain aging, Alzheimer's disease, and mitochondria. Biochim Biophys Acta. 2011; 1812(12):1630-9.

3. Abdo CHN. Sexuality and couple intimacy in dementia. Curr Opin Psychiatry. 2013; 26(6):5938.

4. Choi KB, Jang SH, Lee MY, Kim KH. Sexual life and self-esteem in married elderly. Arch Gerontol Geriatr. 2011; 53(1):17-20.

5. Ascher EA, Sturm VE, Seider BH, Holley SR, Miller BL, Levenson RW. Relationship satisfaction and emotional language in frontotemporal dementia and Alzheimer's Disease patients and spousal caregivers. Alzheimer Dis Assoc Disord. 2010; 24(1):49-55.

6. Mahieu L, Gastmans C. Sexuality in institutionalized elderly: a systematic review of the literature based on ethical argument. Int Psychogeriatr. 2012; 24(3):346-57.

7. Alencar DL, Marques APO, Leal MCC, Vieira JCM. Fatores que interferem na sexualidade de idosos: revisão integrativa. Ciênc Saúde Coletiva. 2014; 19(8):3533-42.

8. Harris SM, Adams MS, Zubatsky M, White M. A caregiver perspective of how Alzheimer's disease and related disorders affect couple intimacy. Aging Ment Health. 2011; 15(8):950-60. 
9. Frugoli A, Magalhães Júnior CAO. A sexualidade na terceira idade na percepção de um grupo de idosas e indicações para educação sexual. Arq Ciênc Saúde UNIPAR. 2011; 15(1):83-95.

10. Bernardo R, Cortina I. Sexualidade na terceira idade. Rev Enferm UNISA. 2012; 13(1):74-8.

11. Montemurro B, Gillen MM. Wrinkles and sagging flesh: Exploring transformations in women's sexual body image. J Women Aging. 2013; 25(1):323.

12. Couto AM, Castro EAB, Caldas CP. Experiences to be a family caregiver of dependent elderly in the home environment. Rev Rene. 2016; 17(1):76-85.

13. Bronner G, Aharon-Peretz J, Hassin-Baer S. Sexuality in patients with Parkinson's disease, Alzheimer's disease, and other dementias. Handb Clin Neurol [Internet]. 2015 [cited 2016 Dec 13]; 130:297-32. Available from: http:// www.sciencedirect.com/science/article/pii/ B9780444632470000171
14. Roelofs TSM, Lujikx KG, Embregts PJCM. Intimacy and sexuality of nursing homes residents with dementhia: a systematic review [Internet]. 2015 [cited 2016 Mar 13]; 27(3):367-84. Available from: https://www.ncbi.nlm.nih.gov/ pubmed/25381794

15. Davies HD, Sridhar SB, Newkirk LA, Beaudreau SA, O'hara R. Gender differences in sexual behaviors of Alheimer disease patients and their relationship to spousal caregiver well-beeing. Aging Ment Health. 2012; 16(1):89-101.

16. Sebold LF, Kempfer SS, Radünz V, Prado ML, Francis Solange Vieira Tourinho FSG, Girondi JBR. Care is... nursing student perceptions: A Heideggerian perspective. Esc Anna Nery. 2016; 20(2):243-7. 